\title{
Scale Matters: A Cost-Outcome Analysis of an m-Health Intervention in Malawi
}

\author{
Erin Larsen-Cooper, MPH, MSW ${ }^{1}$ Emily Bancroft, $\mathrm{MPH}_{1}^{1,2}$ \\ Sharanya Rajagopal, MS, MPH, ${ }^{1,3}$ Maggie O'Toole, $\mathrm{MPH}_{1}{ }^{4}$ \\ and Ann Levin, MA, MPH, $P h D^{5}$ \\ ${ }^{1}$ Health Systems Group, VillageReach, Seattle, Washington. \\ Departments of ${ }^{2}$ Health Services and ${ }^{3}$ Epidemiology, \\ University of Washington, Seattle, Washington. \\ ${ }^{4}$ Concern Worldwide Malawi Programme, Lilongwe, Malawi. \\ ${ }^{5}$ Independent Consultant, Bethesda, Maryland
}

\begin{abstract}
Background: The primary objectives of this study are to determine cost per user and cost per contact with users of a mobile health (m-health) intervention. The secondary objectives are to map costs to changes in maternal, newborn, and child health (MNCH) and to estimate costs of alternate implementation and usage scenarios. Materials and Methods: A base cost model, constructed from recurrent costs and selected capital costs, was used to estimate average cost per user and per contact of an m-health intervention. This model was mapped to statistically significant changes in $M N C H$ intermediate outcomes to determine the cost of improvements in $M N C H$ indicators. Sensitivity analyses were conducted to estimate costs in alternate scenarios. Results: The m-health intervention cost $\$ 29.33$ per user and $\$ 4.33$ per successful contact. The average cost for each user experiencing a change in an MNCH indicator ranged from $\$ 67$ to $\$ 355$. The sensitivity analyses showed that cost per user could be reduced by $48 \%$ if the service were to operate at full capacity. Conclusions: We believe that the intervention, operating at scale, has potential to be a cost-effective method for improving maternal and child health indicators.
\end{abstract}

Key words: mobile health, maternal health, child health, cost-outcome, information and communications technology, economic evaluation

\section{Introduction}

D espite recent gains, improving maternal, newborn, and child health (MNCH) remains an essential health priority for Malawi. Malawi has some of the highest maternal and neonatal mortality rates in the world, with an estimated 360 maternal deaths per 100,000 live births ${ }^{1}$ and 22 neonatal deaths per 1,000 live births. ${ }^{2}$ Many maternal and neonatal deaths can be averted using evidence-based interventions such as utilization of antenatal care, early initiation of breastfeeding, mosquito net use, and timely access to healthcare. However, in Malawi, intractable barriers such as lack of access to expedient health information, poor infrastructure, and long travel distances to health facilities prevent women and children from enacting positive health behaviors and seeking life-saving health services.

Persistent challenges in achieving $\mathrm{MNCH}$ outcomes and the rapid proliferation of mobile phone technologies in low- and middle-income countries have prompted the advent of mobile health (m-health) innovations. In recent years, m-health tools have been used to successfully facilitate obstetric care, ameliorate human resource challenges, and provide information for health promotion. ${ }^{3,4}$ For example, the U.S.-based program text4baby sent text messages to pregnant mothers encouraging healthy attitudes, beliefs, and behavior during pregnancy. Although the program did not lead to significant behavior change, it did increase feelings of being prepared for motherhood among participants. ${ }^{5}$ Similar programs in lowand middle-income countries, such as Wired Mothers in Zanzibar and the Better Border and Healthcare Program in Thailand, have led to positive outcomes. ${ }^{6,7}$

Despite promising evidence on the benefits of such technologies, ${ }^{3,4,8}$ considerable gaps exist in the economic evaluations of m-health interventions. ${ }^{8-13}$ In a global survey on m-health solutions conducted by the World Health Organization, lack of cost-effectiveness data was identified

(c) Erin Larsen-Cooper, et al., 2015; Published by Mary Ann Liebert, Inc. This Open Access article is distributed under the terms of the Creative Commons Attribution Noncommercial License (http://creativecommons.org/licenses/by-nc/4.0/) which permits any noncommercial use, distribution, and reproduction in any medium, provided the original author(s) and the source are credited. 


\section{LARSEN-COOPER ET AL.}

as one of the top four barriers in the implementation of m-health solutions. ${ }^{13}$

We were able to identify one cost analysis of a health intervention in a low-income country with an m-health component: an intervention in Rakai, Uganda that aims to improve AIDS care outcomes through the use of peer health workers. The m-health portion of the intervention used peer health workers' mobile phones to text clinical patient information to central staff, as well as to improve communication. The m-health portion was estimated to cost $\$ 1,046$ annually or $\$ 2.35$ per patient. The authors also estimated that the overall intervention cost $\$ 189$ per virologic failure averted and $\$ 1,025$ per patient lost to follow-up averted; however, it was not possible to determine the cost per outcome associated with the m-health portion of the intervention specifically. ${ }^{11}$

In order to strengthen the knowledge base for the assessment of m-health technology, we have undertaken a costoutcome analysis of an m-health intervention launched in Malawi in 2011. Chipatala cha pa Foni (CCPF), or "health center by phone," consists of a toll-free hotline and a mobile phone-based tips and reminders (T\&R) service seeking to improve MNCH in Balaka District, Malawi. The service targets caregivers of children under 5 years of age, pregnant women, and women of reproductive age. The hotline, staffed by hotline workers trained at similar levels as community health workers, provides callers with timely information and advice on issues across the reproductive and $\mathrm{MNCH}$ spectrum and refers callers displaying symptoms or danger signs to the nearest community health worker or health center for further care. The T\&R messaging service provides weekly text or voice messages to callers who elect to enroll in the service. Messages are personalized for clients based on their week of pregnancy or the child's age and provide accurate information on key health practices.

Users can access the hotline for free from any phone with an Airtel SIM card. Airtel is the largest cellular communications provider in Malawi, and a SIM card costs about $\$ 0.30$. The $T \& R$ messaging service can be accessed for free in one of three ways:

1. Users can receive text messages sent automatically to their phones.

2. Users can receive prerecorded voice messages sent automatically to their phones.

3. Users can retrieve prerecorded voice messages through an interactive voice response (IVR) system. To access CCPF tips and reminders, users call the toll-free IVR system, follow the menu prompts, and then enter the appropriate access code to hear their message. Pregnant women use their estimated due date as their code, and caregivers of children use their child's birth date.

There are three main software applications that support CCPF's services. Hotline workers are guided through health protocols and record information about each call using a customized version of Malawi's electronic health records software created by the Baobab Health Trust (baobabhealth .org/). A customizable software called IntellIVR supports the IVR system. T\&R messages for subscribers are managed through a software application created for CCPF by VillageReach (Seattle, WA).

During the pilot, CCPF was marketed in four health center catchment areas with a population of approximately 150,000 people, including 32,000 women of childbearing age, 24,000 children under 5 years of age, and 7,000 expected pregnancies per year. In order to encourage utilization of the CCPF service, one or two volunteers were chosen in each village to promote the hotline service through one-on-one and small group outreach, distributing flyers, and talking about the CCPF project at community events. Each volunteer was given a lowcost phone in order to provide access to the service to those without personal phones. More detailed results from an independent evaluation of the effect of CCPF on the utilization of home- and facility-based MNCH practices have been reported elsewhere. ${ }^{14}$

The primary objective of this study is to determine cost per user and cost per contact with users of the CCPF service. The secondary objectives are to map costs to statistically significant changes in $\mathrm{MNCH}$ and to estimate costs of alternate implementation and usage scenarios to model future costs per users.

\section{Materials and Methods}

\section{ANALYSIS METHODOLOGY}

The pilot phase of CCPF was implemented over a 21/2-year period from January 2011 to June 2013, with CCPF services launching in July 2011. The authors undertook a costoutcome analysis from the programmatic perspective by calculating the programmatic cost of implementing CCPF from January 1, 2011 to May 31, 2013, as well as the average cost per user and average cost per contact. Service users could access CCPF through any of the following modes of contact: calling the hotline, receiving text or voice messages on their mobile phones, or accessing voice messages by calling an automated IVR system. Only messages successfully sent to or retrieved by users were considered contacts, but the cost of all attempts was factored into the programmatic cost and sensitivity analysis. For example, a text message sent to a phone 


\section{M-HEALTH INTERVENTION COST-OUTCOME ANALYSIS IN MALAWI}

that was turned off would not be considered a successful contact, but the associated charge for attempting to send the message was included in the programmatic cost. The programmatic cost was linked to changes in intermediate health outcomes reported in the independent quantitative evaluation. ${ }^{14}$

\section{INTERVENTION COSTING METHODOLOGY}

A cost analysis was completed using data on program expenditures to estimate total cost of the CCPF pilot. Cost data were taken from program financial records, service level agreements, and the program budget. Costs were classified as recurrent or capital (defined as inputs lasting more than 1 year). Capital costs associated with hardware, as well as equipment, were annuitized over the lifetime of the asset using a social discount rate of 3\%. ${ }^{15}$ All recurrent costs were categorized as follows: administrative, management and oversight, travel and transport, mobilization (demand generation), monitoring, technology-related fees and support, hotline, and T\&R costs. Travel and transport costs included fuel, costs associated with vehicle maintenance, and per diem allowances. Administration costs predominantly included operational expenses such as utilities, rent, and supplies. Expenditures related to the hotline service comprised airtime, hotline worker salaries, and per diem expenses. T\&R service charges primarily included charges for text messages and voice messages sent to subscribers and the cost associated with the IVR system. Both mobilization and monitoring included labor costs, costs associated with training and meeting with volunteers, and cost associated with community events to publicize the service. Management and oversight expenses consisted of staff salaries and associated fringe benefits.

Only capital costs that would be needed to scale-up or replicate the service were included, such as training of hotline workers and volunteers. Most recurrent costs were included, with the exception of international travel and staff time, because these were specifically for the pilot project and are not required for scale-up. Staff was categorized by the location of their work, and salaries and benefits of expatriate staff living in Malawi during the pilot were included in the base model. Because CCPF is currently transitioning program operations to domestic staff, the scale-up of the program should not require significant management and oversight by international staff. Research costs were also excluded from the costing analysis.

All costs in this evaluation have been expressed in U.S. dollars (\$). To ensure comparability across different years, costs were adjusted to the same base year (2013) using the U.S. Consumer Price Index. The cost analysis was conducted using Microsoft (Redmond, WA) Excel ${ }^{\circledR}$ version 14.2.3.

\section{QUANTITATIVE EVALUATION}

The quantitative effects of CCPF on selected MNCH outcomes were determined through a counterfactual analysis using two different sets of comparisons. Details of the statistical analysis have been reported elsewhere, ${ }^{14}$ but this article provides a brief summary of the quantitative methodology. The impact of CCPF on self-reported users was estimated using a treatment-on-the-treated approach. The effect of CCPF on knowledge and behavior of MNCH practices was measured through seven outcomes assessed through baseline and endline surveys. Each outcome was composed of multiple indicators (2-16, depending on the outcome). Outcomes were compared among CCPF users (from the treatment group) and nonusers (from the control group who were predicted as likely to use CCPF had the service been offered in their area) using an instrumented difference-in-difference regression analysis. ${ }^{16}$ The first stage of regression was used to estimate the degree to which treatment assignment (living in an area where CCPF is available) predicted treatment uptake (use of CCPF). In the second stage of regression, the predicted likelihood of CCPF use was regressed on each of the indicators. Results of the regression analysis were estimated in percentage point changes. The quantitative analysis was conducted using Stata version 12.0 software (StataCorp, College Station, TX).

\section{COST-OUTCOME MAPPING METHODOLOGY}

Total programmatic costs from the base cost model were mapped to statistically significant changes in $\mathrm{MNCH}$ intermediate indicators. This provides the average cost per user who experienced an improvement in the knowledge and/or behavior of $\mathrm{MNCH}$ practices. In the quantitative evaluation, separate indicators were used to measure maternal and child health. Hence the total program costs were split evenly between maternal health and child health. This was undertaken in order to minimize the overestimation of cost per additional user.

\section{SENSITIVITY ANALYSIS}

Sensitivity analyses were conducted to estimate costs in alternate implementation scenarios. In the first model (Model 1) we explored the effect of increased use of CCPF on total cost and cost per contact. Specifically, Model 1A examined a scenario wherein hotline and T\&R service operated at the highest rate observed during the pilot over a 2-year period. Model 1B examined costs for the scenario where the hotline operated at maximum capacity. The $T \& R$ has no maximum capacity limitations so the use of the $T \& R$ service was scaled in proportion to the percentage of hotline users who use the $T \& R$ service. In addition, we explored a second model (Model 2) by combining the increased service use in Model 1 with the 


\section{LARSEN-COOPER ET AL.}

removal of costs associated with unsuccessful message $T \& R$ attempts. The cost associated with voice messages was higher than those associated with the text messages. Consequently, in the third model (Model 3), the voice message component (through the IVR) was removed, and its effect was assessed on the total cost and cost per contact.

\section{Results}

There were 9,798 unique users during the CCPF pilot. Of these, 2,699 users were pregnant women, 3,747 were caregivers of children under 5 years of age, and the remaining 3,352 users included nonpregnant women, caregivers of older children, men, or callers with missing data on pregnancy status (Table 1). Because all attempts at reaching users were not successful, Table 1 presents the number of contact attempts, the number of successful attempts, and the proportion of the attempts that were successful.

\section{COSTS}

Between January 2011 and May 2013, the total programmatic cost included in the base model was $\$ 287,357$. This is equivalent to $\$ 29.33$ per user and $\$ 4.33$ per successful contact. Table 2 summarizes the cost profile included in the base cost model.

It should be noted that hotline use varied considerably during the 22-month intervention period, with some of the highest call volumes observed in the months following the hotline launch in July 2011. Hence, hotline-related costs varied over time and were largely driven by service utilization because labor costs were stable (Table 3).

\begin{tabular}{|c|c|c|c|}
\hline $\begin{array}{l}\text { TYPE OF } \\
\text { CONTACT }\end{array}$ & $\begin{array}{c}\text { TOTAL } \\
\text { NUMBER OF } \\
\text { SUCCESSFUL } \\
\text { CONTACTS }\end{array}$ & $\begin{array}{c}\text { TOTAL } \\
\text { NUMBER } \\
\text { OF ATTEMPTS }\end{array}$ & $\begin{array}{c}\% \text { OF CONTACT } \\
\text { ATTEMPTS } \\
\text { THAT WERE } \\
\text { SUCCESSFUL }\end{array}$ \\
\hline Number of calls & 12,210 & - & - \\
\hline $\begin{array}{l}\text { Number of voice } \\
\text { messages retrieved } \\
\text { from IVR }\end{array}$ & 27,157 & 48,481 & $56 \%$ \\
\hline $\begin{array}{l}\text { Number of text } \\
\text { messages (sent to } \\
\text { personal phones) }\end{array}$ & 23,880 & 39,118 & $61 \%$ \\
\hline $\begin{array}{l}\text { Number of voice } \\
\text { messages (sent to } \\
\text { personal phones) }\end{array}$ & 3,193 & 5,685 & $56 \%$ \\
\hline Total & 66,440 & 103,002 & - \\
\hline
\end{tabular}

IVR, interactive voice response.
Table 2. Chipatala cha pa Foni Cost Profile (January 2011-May 2013)

INTERVENTION

COST IN

2013 DOLLARS

(PERCENTAGE

COST CATEGORY

OF TOTAL COST)

Recurrent costs

\begin{tabular}{|c|c|}
\hline Domestic travel and transport ${ }^{a}$ & $27,505(10)$ \\
\hline Administration ${ }^{b}$ & $19,321(7)$ \\
\hline Technology fees and support ${ }^{c}$ & $30,085(10)$ \\
\hline Hotline $^{d}$ service ${ }^{e}$ & $20,549(7)$ \\
\hline Tips and reminders service $^{f}$ & $18,875(7)$ \\
\hline Mobilization ${ }^{9}$ & $37,104(13)$ \\
\hline Monitoring ${ }^{g}$ & $41,161(14)$ \\
\hline Domestic management and oversight & $80,905(28)$ \\
\hline \multicolumn{2}{|l|}{ Capital costs } \\
\hline Annualized one-time costs ${ }^{h}$ & $11,852(4)$ \\
\hline Total & 287,357 \\
\hline
\end{tabular}

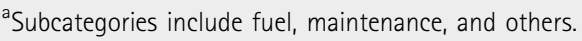

${ }^{b}$ Balaka office-related like rent and utilities, phone and Internet, and others. 'Local and international.

${ }^{\mathrm{d} A i r t i m e}$ labor, and others.

${ }^{\text {e}}$ Due to systems issues on the side of the telecom provider, invoices from the provider often underestimated the total airtime used in a given month, and hence these costs may not reflect the true airtime related expenditures in the future.

fShort message service (texting), voice/interactive voice response, and general. ${ }^{g}$ Labor and general.

${ }^{h}$ Annualized cost included for the entire 2.5-year study period.

\section{INTERVENTION}

Of the $30 \mathrm{MNCH}$ indicators assessed in the treatment-onthe-treated analyses, 10 showed a statistically significant improvement among users of CCPF services (Table 4). For these 10 indicators, CCPF had an effect of 15-80 percentage points, ranging from an estimated 562 to 2,159 users depending on the indicator. For example, after accounting for baseline difference, the proportion of CCPF users who knew the recommended number of times a pregnant women should go for an antenatal care visit was 25 percentage points higher than that of similar nonusers. These changes in percentage points were used to estimate the effect of CCPF on the 2,699 pregnant women who called the hotline during the pilot.

CCPF use had a notable effect of 80 percentage points on the knowledge of care-seeking practices following home births. 


\begin{tabular}{|c|c|}
\hline COST CATEGORY & $\begin{array}{c}\text { LABOR COST IN } \\
2013 \text { U.S. DOLLARS } \\
\text { (PERCENTAGE OF TOTAL } \\
\text { BASE MODEL COST) }\end{array}$ \\
\hline Management and oversight & $80,905(28 \%)$ \\
\hline Hotline service & $10,497(4 \%)$ \\
\hline Mobilization & $21,488(7 \%)$ \\
\hline Monitoring & $36,038(13 \%)$ \\
\hline Total & 148,928 (52\%) \\
\hline
\end{tabular}

Specifically, an estimated 2,159 additional users experienced this indicator compared with nonusers. On average, improvements in knowledge-related indicators were greater than those in behavioral indicators.

\section{MAPPING COSTS AND OUTCOMES}

Among knowledge-based indicators, the average cost incurred by the program for each additional pregnant user reporting a gain in knowledge, ranged from $\$ 67$ to $\$ 355$, whereas the cost for behavioral indicators ranged from $\$ 128$ to $\$ 256$ per user experiencing the outcome. The cost per additional user was lower for indicators such as knowledge of care-seeking practices for home births that experienced substantial improvements compared with those that changed slightly such as breastfeeding practices and knowledge that pregnant women should lift less.
Table 4. Estimated Effect of Chipatala cha pa Foni on Hotline Users During the 2-Year Pilot

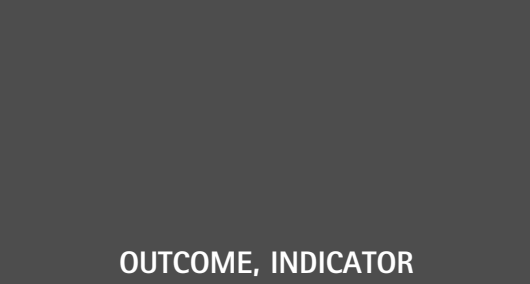

AMONG USERS

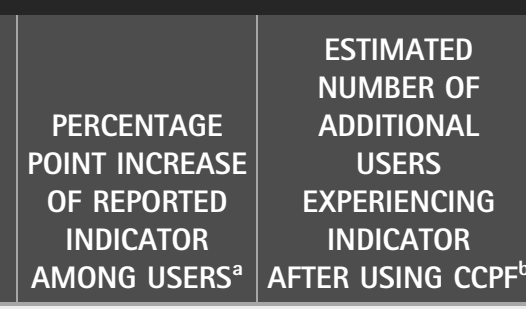

ESTIMATED

NUMBER OF

ADDITIONAL

XPERIENCING

INDICATOR

\section{ESTIMATED TOTAL \\ PROGRAMMATIC COST PER \\ ADDITIONAL USER EXPERIENCING INDICATOR $^{\mathrm{C}}$}

1.1. Knowledge of home and facility-based care

\begin{tabular}{l|c|c|c}
\hline Knowledge of 4+ antenatal care visits & 25 & $675^{\mathrm{d}}$ & $\$ 213$ \\
\hline Knows to drink more water when pregnant & 40 & $1,080^{\mathrm{d}}$ & $\$ 133$ \\
\hline Knows pregnant women should lift less & 15 & $405^{\mathrm{d}}$ & $\$ 355$ \\
\hline $\begin{array}{l}\text { Knows pregnant women should not take } \\
\text { traditional medicines }\end{array}$ & 50 & $1,359^{\mathrm{d}}$ & $\$ 106$ \\
\hline $\begin{array}{l}\text { Can list average number of items to take to a } \\
\text { health center birth }\end{array}$ & 49 & $1,323^{\mathrm{d}}$ & $\$ 109$ \\
\hline $\begin{array}{l}\text { Knows a baby born at home should go to a } \\
\text { health center immediately }\end{array}$ & 80 & $2,159^{\mathrm{d}}$ & $\$ 67$ \\
\hline
\end{tabular}

Behavioral use of home-based practices

\begin{tabular}{l|c|c|c}
\hline Used bednet during pregnancy & 25 & $675^{\mathrm{d}}$ & $\$ 212$ \\
\hline Breastfed within $1 \mathrm{~h}$ of birth & 15 & $562^{\mathrm{e}}$ & $\$ 256$ \\
\hline Child sleeps under bednet & 30 & $1,124^{\mathrm{e}}$ & $\$ 128$ \\
\hline
\end{tabular}

Behavioral use of facility-based practices

\begin{tabular}{c|c|c|c}
\hline Started antenatal care in first trimester & 30 & $1,124^{\mathrm{e}}$ & $\$ 128$ \\
\hline
\end{tabular}

${ }^{a}$ Estimates from the quantitative analysis.

${ }^{b}$ Calculated from $(a \times d)$ or $(a \times e)$ depending on the indicator.

c $\$ 43,629 / \mathrm{d}$.

${ }^{d}$ Estimated change in indicator applied to the subsample of 2,699 pregnant women who called the Chipatala cha pa Foni (CCPF) hotline.

'Estimated change in indicator applied to the subsample of 3,747 callers who were caregivers of children under 5 years of age.

\section{SENSITIVITY ANALYSIS}

Sensitivity analysis showed that total program cost and cost per contact varied significantly across various alternate implementation scenarios (Table 5). Because all scenarios assume increased service use compared with the base model, the total program cost increased in all scenarios. However, the cost per contact declined in both of the higher-volume scenarios, with a substantial reduction of $48 \%$ at full-capacity operation. Improvements in the text message and IVR success rate significantly lowered the cost per contact only at full-capacity operation (Model 2B), as opposed to a marginal drop of roughly $1 \%$ if the hotline had operated at its highest observed volume consistently during the pilot (Model 2A). Likewise, removal of the voice component from the T\&R service was found to be beneficial only at full operational capacity for the hotline, 


\section{LARSEN-COOPER ET AL.}

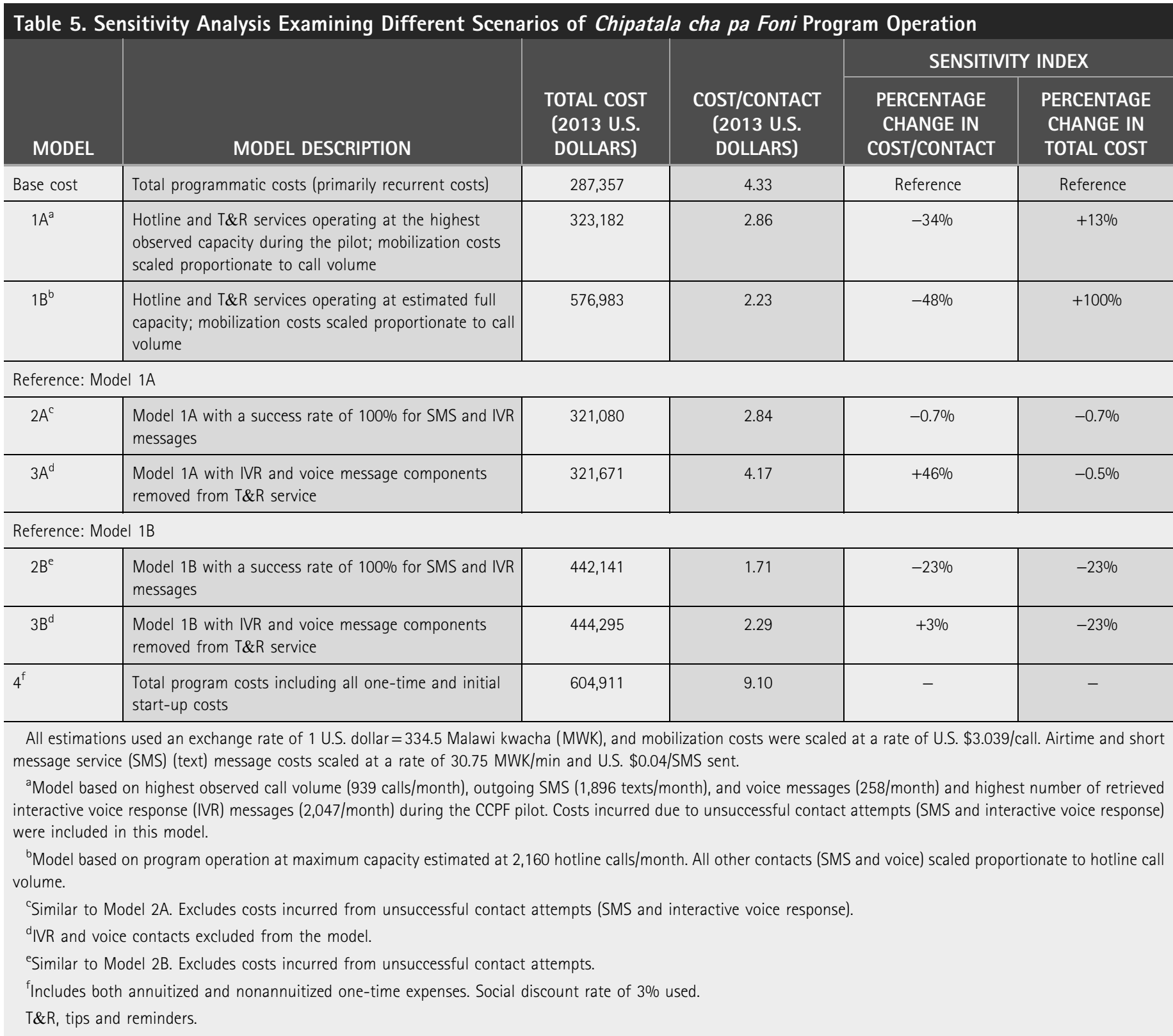

with a slight reduction of $4 \%$ in cost per contact in lower-usage scenarios (Models 3A and 3B).

\section{Discussion}

This economic evaluation provides a detailed description of the costs and benefits identified during the pilot phase of the CCPF program in Balaka, Malawi. The end-line quantitative evaluation showed that CCPF users were significantly more likely than comparable nonusers to experience some intermediate $\mathrm{MNCH}$ outcomes, with the estimated difference ranging from 15 to 80 percentage points. On average, improvements in knowledge-related indicators were greater than those in behavioral indicators. We estimate the total cost of the program to be $\$ 29.33$ per user and $\$ 4.33$ per successful contact. The average cost for each user experiencing a change in an MNCH indicator ranged from \$67 to \$355. This large variation in cost per user experiencing an indicator is due to the large variation in CCPF's impact on the indicators themselves, ranging from 15 to 80 percentage point improvements. 


\section{M-HEALTH INTERVENTION COST-OUTCOME ANALYSIS IN MALAWI}

Sensitivity analysis examined various scenarios of higher service demand and showed that pilot projects such as CCPF are likely to benefit from economies of scale. There are two ways that CCPF could potentially increase utilization: (1) increase the proportion of people living in CCPF's target areas that use CCPF and/or (2) increase CCPF's target area. During the pilot, the uptake of CCPF in treatment communities was roughly $20 \%$, even though more than $75 \%$ of the target population had heard of the hotline service. Qualitative data from an independent evaluation ${ }^{14}$ suggested low perceptions of need, cultural barriers, and limited access to phones as barriers to accessing CCPF. Since the pilot, CCPF has expanded its target area to a total of four districts. Not surprisingly, this has led to a corresponding increase in call volume. In February 2014, the Reproductive Health Unit of Malawi's Ministry of Health endorsed CCPF and stated its desire to see the program scale nationally. CCPF is expected to double the number of districts where it is offered by 2016, and it is likely that as CCPF continues to expand its user base, it will begin to operate at lower cost per contact. Thus CCPF will likely reach the capacity explored in Model 1B simply by increasing its target area. As the sensitivity analyses showed, this increased utilization will likely reduce the cost per contact.

To our knowledge, this is the first cost-outcome evaluation of an m-health technology targeting maternal and child health outcomes. As in any economic evaluation, the current analysis has certain limitations. Our cost estimates are likely exaggerated because total programmatic costs could not be disaggregated by service type so we had to divide costs 50-50 between maternal and child health services. We were also unable to account for users who may have experienced more than one outcome as a result of using CCPF. Another limitation was the exclusion of volunteer time from total costs. Volunteers primarily contributed to demand generation. However, monetization of their time was not feasible because it was challenging to delineate their share of the output or direct contributions. They were, however, compensated with drinks and snacks at monthly meetings and other small incentives, the costs for which have been included under mobilization activities. Additionally, in the sensitivity analyses, costs incurred from mobilization events have been proportionately scaled-to account for the increased support that would need to be provided to volunteers.

As interest in m-health interventions increases at the local, national, and global levels, it is becoming increasingly important to assess the cost-effectiveness of these types of interventions in relation to similar interventions. In and of itself, cost-outcome analyses such as ours do not monetize the benefits of the program to allow a cost-benefit analyses or easy comparison with the cost-effectiveness of other programs. This analysis takes into consideration costs only from the program provider perspective; comparing costs and cost savings from the perspective of users and the health system would paint a fuller picture of economic implications of CCPF.

\section{Conclusions}

The CCPF pilot led to significant changes in knowledge and behavior among those who use it. We believe that CCPF, operating at scale, has potential to be a cost-effective method for improving maternal and child health indicators. M-health projects have the potential to reduce time, distance, and cost of health education and healthcare. ${ }^{9}$ As CCPF scales up, further research is needed to understand the economic implications of CCPF from different perspectives, including potential cost savings to the national health system and individual users and comparative cost-effectiveness in relation to other maternal and child health programs.

\section{Acknowledgments}

The CCPF pilot was funded through Concern Worldwide's Innovations for Maternal, Newborn \& Child Health Initiative. Implementation was led by VillageReach, in partnership with the Malawi Ministry of Health and the Baobab Health Trust. The authors would like to thank Aimee Desrochers, for her edits and suggestions that were helpful in creating a clear and concise manuscript, and the reviewers, whose comments led to a stronger article.

\section{Disclosure Statement}

No competing financial interests exist.

\section{REFERENCES}

1. WHO, UNICEF, UNFPA, The World Bank, the United Nations Population Division. Trends in maternal mortality: 1990 to 2013. Geneva: World Health Organization, 2014.

2. UNICEF. Committing to child survival: A promised renewed-Progress report 2014. New York: UNICEF, 2014.

3. The Center for Innovation \& Technology in Public Health, Public Health Institute, Oakland, CA. Leveraging mobile technologies for maternal, newborn and child health. November 2012. Available at www.mhealthknowledge .org/sites/default/files/17_leveraging_mobile_technologies_to_promote_ maternal_newborn_health.pdf (last accessed March 15, 2015).

4. Tamrat $T$, Kachnowski S. Special delivery: An analysis of $m$-Health in maternal and newborn health programs and their outcomes around the world. Matern Child Health J 2012;16:1092-1101.

5. Evans WD, Wallace JL, Snider J. Pilot evaluation of the text4baby mobile health program. BMC Public Health 2012;12:1031.

6. Lund S, Hemed M, Nielsen BB, Said A, Said K, Makungu MH, et al. Mobile phones as a health communication tool to improve skilled attendance at 


\section{LARSEN-COOPER ET AL.}

delivery in Zanzibar: A cluster-randomised controlled trial. BJOG 2012;119:1256-1264.

7. Kaewkungwal J, Singhasivanon $P$, Khamsiriwatchara $A$, Sawang $S$, Meankaew P, Wechsart A. Application of smart phone in "Better Border Healthcare Program": A module for mother and child care. BMC Med Inform Decis Mak 2010;10:69.

8. Philbrick WC. m-Health and MNCH: State of the evidence. January 2013. Available at http://www.mhealthknowledge.org/sites/default/files/ 15_un_007_evidencegapreport_digital_aaa.pdf (last accessed March 15, 2015).

9. Aranda-Jan C, Mohutsiwa-Dibe, Loukanova S. Systematic review on what works, what does not work and why implementation of mobile health (mHealth) projects in Africa. BMC Public Health 2014;14:188.

10. Schweitzer J, Synowiec C. The economics of eHealth and mHealth. $J$ Health Commun 2014;17(Suppl 1):73-81.

11. Chang LW, Kagaayi J, Nakigozi G, Serwada D, Quinn TC, Gray RH, Bollinger RC, Reynolds SJ, Holtgrave D. Cost analyses of peer health worker and mHealth support interventions for improving AIDS care in Rakai, Uganda. AIDS Care 2012;25:652-656.

12. Leo $N$, Schneider H, Daviaud E. Applying a framework for assessing the health system challenges to scaling up mHealth in South Africa. BMC Med Inform Decis Mak 2012;12:123.

13. World Health Organization. M-health: New horizons for health through mobile technologies: Second global survey on health. Geneva: World Health Organization, 2011.
14. Invest in Knowledge. Evaluation report of information and communications technology for maternal, newborn and child health project: Improving access to reproductive, maternal, and newborn health information and services in Malawi. 2013. Available at http://innovationsformnch.org/uploads/ resources/pdfs/ICT_for_MNCH_Report_131211md_FINAL,_AY_to_Gates_ language.pdf (last accessed March 1, 2015).

15. Drummond $M$, Weatherly $H$, Ferguson B. Economic evaluation of health interventions. BMJ 2008;337:a1204.

16. Duflo E. Schooling and labor market consequences of school construction in Indonesia: Evidence from an unusual policy experiment. Am Econ Rev $2001 ; 91: 795-813$.

Address correspondence to: Erin Larsen-Cooper, MPH, MSW VillageReach

2900 Eastlake Avenue E., Suite 230 Seattle, WA 98102

E-mail: erin.larsen-cooper@villagereach.org

Received: April 8, 2015

Revised: July 28, 2015

Accepted: July 20, 2015 